\title{
NEGATIVITY EFFECT AND THE EMERGENCE OF IDEOLOGIES ${ }^{*}$
}

\author{
Enriqueta Aragones $^{* *}$
}

January 1994

Revised: December 1995

* I wish to thank V.V. Chari, Tim Feddersen, Ehud Kalai, Mort Kamien, Ken Kollman, Roger Myerson, Zvika Neeman, Scott Page, Stan Reiter, German Rojas, Don Saari, David Schmeidler, Avner Shaked, and three anonymous referees for their helpful comments. I am greatly indebted to Itzhak Gilboa for his valuable suggestions and his guidance. Financial support from FPU-MEC (Spain) is gratefully acknowledged.

** Departament d'Economia, Universitat Pompeu Fabra, Carrer Balmes 132, 08008 Barcelona (Spain). e-mail: aragones@upf.es 


\begin{abstract}
"Negativity effect" refers to the psychological phenomenon that people tend to attach greater weight to negative information than to equally extreme and equally likely positive information in a variety of information processing tasks. Numerous studies of impression formation have found that negative information is weighted more heavily than positive information as impressions of others are formed. There is empirical evidence in political science that shows the importance of the negativity effect in the information processing of the voters. This effect can explain the observed decrease of popularity for a president the longer he is in office.

We construct a dynamic model of political competition, incorporating the negativity effect in the decision rule of the voters and allowing their preferences to change over time, according to the past performance of the candidates while in office. Our model may explain the emergence of ideologies out of the competition for votes of myopic candidates freely choosing policy positions. This result gives rise to the formation of political parties, as infinitely-lived agents with a certain ideology. Furthermore, in this model some voters may start out by switching among parties associated with different policies, but find themselves supporting one of the parties from some point on. Thus, the model describes a process by which some voters become identified with a "right" or "left" bloc, while others "swing" between the two parties.
\end{abstract}




\section{INTRODUCTION}

"Negativity effect" refers to the psychological phenomenon that people tend to attach greater weight to negative information than to equally extreme and equally likely positive information in a variety of information processing tasks. Numerous studies of impression formation have found that negative information is weighted more heavily than positive information as impressions of others are formed (negative effects have greatest influence on final judgements).

The negativity effect has important implications in political science. During a campaign, candidates project to voters their personalities as well as information regarding their political views and future performance. Before the election voters process all the information and impressions that they have been gathering during the campaign. Thus, the negativity effect may be relevant to the analysis of voters' behavior. Indeed, there is empirical evidence that shows the importance of negative features in the information processing of the voters.

Kernell (1977) and Lau (1982) detected negativity effect in congressional and presidential elections: Kernell (1977) studied congressional elections in the United States from 1946 to 1966 and found that disapproval of the president's job performance had stronger effects on congressional voting than did approval of the president's job performance (off-year congressional elections are often considered a referendum on the president's job performance). Lau (1982) replicated Kernell's findings for the 1974 and 1978 congressional elections, and further found that evaluations of the presidential candidates in 1968, 1972, and 1980 were more strongly shaped by negative information about the candidate than positive information.

The negativity effect characterizes impressions formed from trait and behavioral information. There are several different explanations of the negativity effect (for a survey see Kanouse and Hanson (1972)). We discuss the two more relevant explanations to political behavior. The "figure-ground" hypothesis proposes a perceptual explanation. The negativity effect occurs because negative actions are contrasted with the generally positive expectations of presidential candidates' behavior. This hypothesis claims that behavior that deviates from 
socially prescribed norms is seen as indicative of "true" personality. There are many reasons to follow norms, and to do what is expected. The perceiver (voter) will judge the commendable behaviors to be of questionable authenticity, while there is seldom any reason to simulate unfavorable characteristics. Similarly, there are strong norms against expressing negative evaluations of others. Nonnormative behavior is more likely to reflect the true characteristic of the person who is being evaluated because it is manifested in spite of sanctions against it. A related explanation involves infrequency. Less frequent information might be more influential because it is more salient, easily noticeable and readily processed. Thus, this theory concludes that unexpected, counter-normative behavior is very credible and therefore more informative about personality than expected, normative behavior.

A second explanation of the negativity effect is dubbed the "cost orientation" or "risk aversion" explanation (Abelson and Levi (1985)). It is motivational in nature: people are more motivated to avoid costs than to approach gains: the potential costs of trusting someone who proves to be unworthy often outweigh the potential gains. Therefore, it is always safer to make the more negative evaluation when evidence is mixed. One reason for the development of such motivations might be evolutionary: it may be more adaptive to avoid costs than to approach gains when the objective is to maximize the probability of survival.

Lau (1985) and Klein (1991) test these two explanations of the negativity effect, namely, the figure-ground hypothesis and the cost orientation hypothesis. Lau shows that the way political figures are evaluated may change with a changing political environment. The dynamics of political evaluation are different for different types of political figures (presidents, congresspersons, etc.). In support of the figure-ground explanation, Lau (1985) found that voters who held the government in high esteem (and therefore were likely to hold positive expectations of politicians) showed a greater negativity bias in their evaluations of candidates than voters who held negative opinions of the government. In support of the cost orientation explanation, Lau found that respondents who cared most about the outcome of the election showed the greatest negativity effect. Klein (1991) analyzed the 1984 and 1988 presidential elections and found 
that character weaknesses were more important than strengths in determining the public's evaluations of the candidate and the ultimate vote.

In this paper we develop a formal model of electoral competition, which focuses on the implications of the negativity effect. In accordance with the findings quoted above, our model assumes that it is dissatisfaction, rather than satisfaction with government policies that drives voters' choices. In other words, voters vote against rather than for parties. Furthermore, we focus on negative impressions which are formed as a result of candidates' performance in the past. That is, we ignore other sources of information about candidates such as their platforms, personal lives and highlight their performance in office.

While some of the studies mentioned above focus on negative information about candidates' personalities, there is also empirical support to a negativity effect with respect to candidates' performance. Campbell et al. (1960) argue that a president's party is hurt by negative events occurring during his administration but not helped by positive events. Some studies of the effects in political behavior using aggregate data give evidence of this fact. Mueller (1973) shows that worsening the economic conditions hurts presidential popularity. Bloom and Price (1975) show that it hurts the incumbent reelection chances. But both stated that improving economic conditions did not similarly help them.

There is also evidence that points to the fact that a president's popularity tends to decline the longer he is in office. Mueller (1973) shows that from 1950 to 1972, popularity clearly decreases for every president of the United States, except Eisenhower1, 2 .This phenomenon is typically attributed to what Downs (1954) called the "coalition of minorities." He presented a set of conditions under which the opposition party can always defeat the incumbent. The strategy of the opposition would be to abandon the position of the majority on some issues in order to create a coalition among the voters that disapprove of the government's performance. Downs claims that this strategy will allow the opposition to win

1 Even in Eisenhower's case, the popularity index did not rise over time. It didn't show a great variability in the face of good economic conditions that did not require major changes on the administration's part.

2 While this fact can also be due to inflated initial approval ratings, it is certainly consistent with the negativity effect explanation. 
the election if the incumbent has been in office long enough. In this case, the government's party is held responsible for many decisions, and as a consequence, the number of voters that disapprove of their performance increases. According to Downs, it is also necessary that voters have a stronger preference for the policies they favor when in the minority than for those they favor when in the majority. Thus, the negativity effect seems to have an implicit role behind Downs assumptions.

The natural way to capture the negativity effect is to think of elections as repeated over time. Thus, in a dynamic setting, we can consider the past performance of the parties while in office as the most reliable information that is readily available to the voters. In the model presented here, the record that voters keep of the parties will reflect how much they disliked them rather than how much they liked them, and this record is updated every time that a new party takes office. The cumulative negativity effect implies that voters get more tired of parties the longer they are in office.

More specifically, at each time $t$ voters face a new decision problem represented by an election. Before each election voters update their evaluation of the parties by applying a discount factor $\delta$, and take into account the results of the last election, given by the last party in office (the incumbent at the time of the election) and the policy it chose to implement. The utility that voter $i$ derives from the policy $w$ implemented by the winning party at a given time is given by $u_{i}(w)$. The evaluation of each party by such a voter represents the discounted sum of the utilities that the voter has derived from the policies implemented by this party in the past. Thus, if $p$ denotes the incumbent, the evaluation of the parties by voter $i$ at time $T$ is given by the following cumulative dissatisfaction indices ${ }^{3}$ :

$$
U_{i}^{T}(p)=u_{i}\left(w^{T-1}\right)+\delta U_{i}^{T-1}(p) \quad \text { and } \quad U_{i}^{T}\left(p^{\prime}\right)=\delta U_{i}^{T-1}\left(p^{\prime}\right), \text { for } p^{\prime} \neq p
$$

This decision rule reflects the fact that the evaluation of parties by the voters is constantly changing over time as new parties are taking office. Since, as

3 This decision rule may be viewed as a variant of the theory of repeated choice with cumulative utility functions suggested in "Case-Based Consumer Theory" by Gilboa and Schmeidler (1993). However, we do not presuppose acquaintance with their model. 
we have argued, voters get more tired of parties the longer they are in power, $u_{i}(\cdot)$ will be assumed negative and will represent the dissatisfaction of the voter with respect to the policy chosen by the party. Finally, $\delta \in(0,1)$ represents the factor by which past periods are discounted. The discounting reflects the fact that more recent periods are deemed more relevant, and are more likely recalled than less recent ones. Later, we will identify three factors determining the voters choice: "ideology", which is roughly represented by the utility $u_{i}(\cdot)$; "recency" which is reflected in the discount factor $\delta$; and "frequency" which is taken into account in the summation operation.

Note that we focus on the voters' dissatisfaction with parties, rather than with candidates or with policies. The dissatisfaction is not defined per candidate, since these are assumed to be newly replaced every election. Likewise, while voters may be dissatisfied with a certain policy, they do not get to choose policies directly. Thus it is the dissatisfaction with parties that matters, because parties are the alternatives voters choose from in any given election.

Given the decision rule of the voters we have sincere voting. Each voter has a single vote to cast and, because our voters do not consider the possibility of abstention, all votes are to be cast. There is a continuum of voters who differ in their preferences for the two types of policies.

The decision rule used by our voters resembles the "'on-line' impression based model" of candidate evaluation described and tested by Lodge et al. (1989). In this model voters process the information they receive about the candidates at the moment of exposure, by entering their impressions into their evaluative tally. They test this model against another model of candidate evaluation based on the information kept in the memory of the voters. They conclude that people do not rely on the specific candidate information available in memory; rather voters form their judgments when the information is encountered. In our model, after seeing the result of an election, voters update their evaluations of each party by discounting their previous evaluation, and adding the evaluation of the last performance of the incumbent.

There exist some theories of voting which suggest that voters base their decision on past performance of the parties. The Reward-Punishment theory proposed by Key (1966) is based on the assumption that voters only care about 
the effects of the policies that parties choose and they are looking at past performance when deciding how much confidence to give to each party. Downs (1957) proposed a theory according to which parties' past performance is the cheapest way for voters to predict future performance. In his model, voters care about the policy that a party implements on top of its effects. He assumes that political parties must be consistent over time in the policies they advocate and implement. Our interpretation of the voters' behavior is different from Downs' but we find that consistency over time in the policies implemented is a result of optimal choice of the parties. Fiorina (1981) builds a dynamic model for two parties that combines features of both theories and examines it at the empirical level. He assumes that voters base their decision not only on past performance of the parties but also on past promises and hypothetical choices of policies. He shows that most of the assumptions of his theory are supported by the data. Our model is much simpler than Fiorina's. Past promises or hypothetical choices are not considered by the voters in their evaluation of the parties. For simplicity we also assume that platforms have no effect on the evaluation of the parties.

A fixed number of parties compete in all elections ${ }^{4}$. Each party presents one candidate to each election. Candidates do not have ideal points with respect to policies to begin with. These are endogenously determined by the choices that maximize their share of votes. Candidates know the decision rule of the voters. Therefore there is no need to present platforms before elections, since voters make their decision based solely on past performance. There is a single-winner elected under majority rule. The winner of the election has to choose a policy to implement. For simplicity, we assume that the strategies available to candidates consist of only two different types of policies $\{0,1\}$. What is a candidate's goal, once in office? We assume that it is to maximize her party's popularity in the next election, even if this election is doomed to be a defeat. Shouldn't she be interested in future elections as well? Specifically, if candidates engage in longrun strategic considerations, they may be willing to sacrifice popularity in the next election in order to gain support in the following one. However we do not find these long-run considerations very appealing. Candidates face uncertainty regarding their political lifetime. Not knowing how long they would represent

4 First, we develop a model of two-party competition, and then we extend the results for a model with three-parties. 
their parties it seems plausible that they would be "impatient" and behave myopically. Thus, at each time $t$, the candidate that wins the election, implicitly assumed to know the decision rule of the voters and the location of the median, chooses a policy in the set $\{0,1\}$ to maximize the proportion of votes that she can obtain in the next election (stagewise vote-maximizer).

The choice of these assumptions is made in order to have the simplest model that would capture the negativity effect on the behavior of the voters. The decision rule that voters use in this model differs in many way from the standard literature, but the primitives of this rule conform with standard theories of elections. The simplicity of the policy space and the objective of the parties is needed to enhance the implications of the behavior of the voters. As a consequence, a unidimensional policy space enables us to capture the negativity effect without having to deal with the complications of higher dimensions.

Our model ignores parties' platforms. Thus, a party is "ideological" if it behaves according to an ideology, that is, if its implemented policies exhibit consistent patterns. In order to define "ideological behavior" we therefore need at least two policies. We say that a party behaves ideologically if it always makes the same choices, or at least makes the same choice from a certain time on. Alternatively, a party that keeps switching between policies does not behave ideologically. For simplicity, we analyze a model with only two possible policies 5 .

In the model with two parties we find that each party behaves according to some ideology, when their only objective is the maximization of the votes. That is, if the preferences of the median voter between the two types of policies are not very extreme, the solution of this model shows that no party mixes policies of different types, i.e., if the first candidate of a party starts choosing a policy of type 1 , all candidates representing this party in the future will continue by choosing this type of policy, as the policy that maximizes the number of votes for the party. Given the myopic competition of candidates we thus find that each party "specializes" in a different type of policy. Nevertheless, from an outside

5 The model may be easily extended to more than two policies. The results, however, will depend on the specific assumptions made regarding the distribution of voters' preferences. 
point of view, it may seem that the parties had an ideal point in the policy space, and their only objective is to implement it. Since we assume that parties and candidates have no ideal points to begin with, this result can be interpreted as suggesting that ideologies may emerge from the actions of the candidates when maximizing the popularity of the party in the short run. Thus, the competition of myopic candidates that behave independently of the party label assigned to them gives as a result the characterization of political parties by ideologies.

The fact that different parties tend to be associated with different ideologies is supported by evidence. Empirical studies lend support to the claim that Democrats and Republicans have different effects on the economy while in office. Hibbs (1977), Beck (1982), and Chappel and Keech (1986) show that they have different effect on the unemployment rate. Alesina and Sachs (1988) and Tabellini and La Via (1989) show that republican administrations have been associated with tighter monetary policies. Frey and Schneider (1978) found that conservative presidents tend to restrict expenditures. However, as opposed to classical models which assume that ideologies are primitive, we show that they may emerge from each party's attempt to disassociate itself from its competitor's weaknesses.

We also analyze the behavior of the voters over time. We observe that more extremist voters identify with the party that chooses their most preferred policy, while a proportion of moderate voters (closer to the median) will always switch between the two parties and always vote for the party that will end up winning the election. Thus, in the long run we obtain three different groups of voters: leftist, rightist, and swing voters.

Finally, we analize a model of multiparty competition, based on the same assumptions. We find that the emergence of ideologies is robust to this change, that is, even when there are more than two parties competing in all the elections, it is choosing always the same type of policy that maximizes their votes. With this model we also analize the case in which parties, instead of candidates, are the players of the game. Since parties participate in elections at all periods, they care about the future, and if they were to decide on policies, their objective would be to maximize the number of times that they will be in office over time. We find conditions under which the equilibrium strategies resulting of the parties' game coincides with the strategies that sequences of myopic candidates 
would choose. Thus, we show the compatibility of the different objectives of parties and candidates. We interpret this result as the formation of political parties, as infinitely-lived agents with a certain ideology, out of the competition of myopic candidates freely choosing policy positions.

The rest of the paper is organized as follows: section 2 describes the model formally. In section 3 we present the results. In section 4 we generalize the model to multiparty competition. And section 5 includes some concluding remarks.

\section{THE MODEL}

At each time $t=0,1,2, \ldots$ an election takes place. There are two parties, $a$ and $b$, that compete in all elections. At each election $t$ we have two candidates (one for each party) competing for votes. At each time $t$ the party that obtains the largest proportion of votes wins the election (majority rule). In case of a tie, nature chooses one of the parties with equal probability. After the election, the candidate of the winning party has to choose a policy $w^{t}$. We assume that at each time $t$, the candidate that wins the election, knowing the decision rule of the voters and the location of the median, chooses a policy in the set $\{0,1\}$ to maximize the proportion of votes that she can obtain in the next election (stagewise vote-maximizer).

At each election $t$, the evaluation of the parties by the voters is given by their cumulative dissatisfaction indices at that time. If at time $t$ party $a$ is the incumbent, the cumulative dissatisfaction indices of voter $i$ are:

$$
U_{i}^{t}(a)=u_{i}\left(w^{t-1}\right)+\delta U_{i}^{t-1}(a) \quad \text { and } \quad U_{i}^{t}(b)=\delta U_{i}^{t-1}(b)
$$

Similarly, if at time $t$ party $b$ is the incumbent, then the cumulative dissatisfaction indices are:

$$
U_{i}^{t}(b)=u_{i}\left(w^{t-1}\right)+\delta U_{i}^{t-1}(b) \quad \text { and } \quad U_{i}^{t}(a)=\delta U_{i}^{t-1}(a)
$$

Where $0<\delta<1$ is the discount factor. At time $t=0$ we have $U_{i}^{0}(p)=0$ for all voters and all parties. Voters give their vote to the party that gives them the highest cumulative dissatisfaction index. If a voter is indifferent between the two parties, she will vote for each of them with equal probability. We will assume 
that the law of large numbers holds, i.e., that if a proportion $\mu$ of voters are indifferent between the two parties, each party gets a proportion $\frac{\mu}{2}$ of their votes $^{6}$.

Each voter $i$ is characterized by two instantaneous "dissatisfaction indices" corresponding to the two different types of policies that parties may implement while in office: $u_{i}(0)=\alpha_{i}<0$ represents the dissatisfaction of voter $i$ with policies of type 0 . Similarly, $u_{i}(1)=\beta_{i}<0$ represents the dissatisfaction of voter $i$ with policies of type 1 . The relative dissatisfaction of voter $i$ with respect to the two different types of policies can be characterized by the ratio $x_{i}=\frac{\alpha_{i}}{\alpha_{i}+\beta_{i}}$. Alternatively, we may re-scale each voter's dissatisfaction indices so that $\alpha_{i}+\beta_{i}=-1$. Thus, we can write $u_{i}(0)=-x_{i}$, and $u_{i}(1)=-\left(1-x_{i}\right)$. Given the history of a party, the evaluation of the voters takes into account the cumulative dissatisfaction with respect to its past performance, by adding the discounted indices of dissatisfaction corresponding to the policies implemented by the party when in office. We assume a continuum of voters with "relative dissatisfaction indices" distributed on $[0,1]$. Let $x_{I}(t)$ denote the relative dissatisfaction index of the indifferent voter at election $t$.

\section{RESULTS.}

In this section we solve the model described previously by induction, and we find the following results.

\section{Theorem 1: Choices of Candidates}

If the relative dissatisfaction index of the median voter lies in the interval $\left(\frac{\delta}{1+\delta}, \frac{1}{1+\delta}\right)$, then we have the following results up to any permutation of parties and/or of policies:

(i) party $a$ always chooses policies of type 0 and party $b$ always chooses policies of type 1 ,

(ii) parties always alternate in office.

6 See Judd (1985) for the mathematical subtleties involved. 
Formally, for $k=0,1,2, \ldots$, at $t=2 k$ we have $p^{t}=a$ and $w^{t}=0$; at $t=2 k+1$ we have $p^{t}=b$ and $w^{t}=1$.

(All proofs are relegated to an appendix.)

Theorem 1 states that, under the above assumptions, all candidates that represent a certain party will always choose the same type of policy. It also states that up to any period $t=2 k$, party $a$, which has been choosing policies of type 0 , wins one half of the time and party $b$, which has been choosing policies of type 1 , also wins one half of the time. The solution of the "candidates' game" shows that in the long run each party chooses the same type of policy, different from the opponent's, and wins one half of the time. That is, candidates whose sole objective is to win the election (maximize their share of votes) have no incentive to deviate from the ideology that characterizes the party they belong to.

By analyzing the evolution of the relative dissatisfaction index of the indifferent voter at different elections we find a particular trend in the evolution of the decisions of the voters over time. It is described in the following theorem.

\section{Theorem 2: Choices of Voters}

Assume without loss of generality that $x^{0}=0$. If the relative dissatisfaction index of the median voter lies in the interval $\left(\frac{\delta}{1+\delta}, \frac{1}{1+\delta}\right)$, then for $k=1,2, \ldots$, the relative dissatisfaction index of the indifferent voter at $t=2 k$ is $x_{I}(2 k)=\frac{1}{1+\delta}$ and at $t=2 k+1$ is $x_{I}(2 k+1)=\frac{\delta}{1+\delta} \frac{1-\delta^{2 k}}{1-\delta^{2 k+1}}$, with $\frac{\partial x_{I}(2 k+1)}{\partial k}>0$ and $\lim _{k \rightarrow \infty} x_{I}(2 k+1)=\frac{\delta}{1+\delta}$.

If we assume that the party that won the first election chose a policy of type 0 (when it was indifferent between the two types of policies), then the relative dissatisfaction index of the indifferent voter at each election divides the voters in two groups. The voters with a larger relative dissatisfaction index vote for the party that chooses policies of type 1, and voters with a smaller dissatisfaction index vote for the party that chooses policies of type 0 . Thus, this result shows how different groups of voters obtain. Voters in each group exhibit the same behavior in all but the very first election (in which everybody 
randomizes). The group of voters with relative dissatisfaction indices larger than $\frac{1}{1+\delta}$ always vote for the party that chooses policy 1 . Voters with relative dissatisfaction indices between $\frac{\delta}{1+\delta}$ and $\frac{1}{1+\delta}$ always alternate between the two parties, and at each election vote for the winner. Voters with relative dissatisfaction indices between $\frac{\delta}{1+\delta+\delta^{2}}$ and $\frac{\delta}{1+\delta}$ start out by switching between the two parties, but for each of them there is a time after which she will only vote for the party that chooses policy 0 . Finally, voters with relative dissatisfaction indices smaller than $\frac{\delta}{1+\delta+\delta^{2}}$ always vote for the party that chooses policy 0 . Figure 1 shows the distribution of the different groups of voters.

Theorem 2 shows that, while more extremist voters identify with the party that always chooses their most preferred policy, some voters with more moderate preferences will always vote for the party that has been either less times in office or, if both parties have won the same number of elections, for the party that has been less recently in office. The proportion of voters that swing between the two parties decreases over time, as more voters become identified with one of the parties (this is implied by the sign of the derivative of the relative dissatisfaction index of the indifferent voter at $t=2 k+1$ with respect to time).

To better understand this result, we note that there are two main factors which determine the magnitude of the negativity effect, on top of the voters' relative dissatisfaction indices: the frequency and the recency of negative experiences. Thus, at an odd election $t=2 k+1$ the first winner, say party $a$, has been in office more times than party $b(k+1>k)$ and "more recently": for every time $b$ was in office there is a more recent time in which $a$ was in office (and this is a one-to-one correspondence). Hence, both frequency and recency effects are favoring party $b$. By contrast, at an even period $t=2 k$ only the recency effect differentiates between the two parties.

The preferences of the voters are also determined by their relative dissatisfaction index, which may be viewed as their "ideology". In particular, extreme "leftist" or extreme "rightist" voters will not switch between the parties. Thus, their behavior is consistent with the supposition that they are loyal to some 
ideology. Differently put, a special case of dynamic choice driven by the negativity effect may be described as ideological voting. For extreme voters, the "ideology" (given by the relative dissatisfaction index) dominates both frequency and recency effects. However, negativity effect also predicts that some voters, and with them the majority, will switch between parties. This is explained by the fact that, for voters with more moderate preferences, the frequency and/or recency effects dominate their "ideological bias".

Note that Theorem 2 predictions are asymmetric with respect to the two parties: the party which was first to win an election has fewer "partisans" than its opponent. This asymmetry is due to the following fact: the party that wins the first election (in which all voters randomize) will lose at all odd elections because it has been in office more recently and more often than its opponent. On the other hand, the party that loses the first election will lose at all even periods, that is, when both parties have been in office the same number of times, but it won more recently. Thus, the party that wins the first election will suffer a negativity effect due to both recency and frequency, while its opponent suffers from recency alone. Thus, if we consider two voters $i$ and $j$ who are symmetric with respect to one half $\left(x_{i}=1-x_{j}\right)$, it is possible that one of them is "loyal" to the party that was the second winner, while the other is not loyal to the first winner. As time goes by, the frequency effect becomes less important due to the voters' fading memory: for a large enough $T$ the effect of the first winner-discounted by $\delta^{T}-$ shrinks to zero. Hence, in the long run the recency effect prevails and the asymmetry disappears.

It is worth noticing that symmetric results obtain if voters recall the results of a finite number of the most recent elections. Suppose that at time $T$ all voters have memory $M^{T}=\left\{\left(t, p^{t}, w^{t}\right): T-T^{*} \leq t \leq T-1\right\}$ of the most recent $T^{*}$ elections. An element of memory is represented by $m^{t}=\left(t, p^{t}, w^{t}\right)$ where $p^{t}$ represents the party that won the election at time $t$ and $w^{t}$ the type of policy it implemented. The memory of voters in updated after each election by including the results of the most recent election and dropping the less recent ones. At $t=0$ we have $M^{0}=\varnothing$. The cumulative dissatisfaction indices of voter $i$ at time $T$, are given by: 


$$
U_{i}^{T}(a)=\sum_{\left(t, a, w^{t}\right) \in M^{T}} \delta^{T-t-1} u_{i}\left(w^{t}\right) \text { and } U_{i}^{T}(b)=\sum_{\left(t, b, w^{t}\right) \in M^{T}} \delta^{T-t-1} u_{i}\left(w^{t}\right)^{7}
$$

\section{Theorem 3: Finite Memory}

If the relative dissatisfaction index of the median voter lies in the interval $\left(\frac{\delta}{1+\delta}, \frac{1}{1+\delta}\right)$, and the memory of the voters at each time $T$ is such that $M^{T}=\left\{\left(t, p^{t}, w^{t}\right): T-T^{*} \leq t \leq T-1\right\}$ then for $t>T^{*}$ and for $k=1,2, \ldots$, the relative dissatisfaction index of the indifferent voter is

if $T^{*}$ is odd $\quad x_{I}(2 k)=\frac{1}{1+\delta} \frac{1-\delta^{T^{*}+1}}{1-\delta^{T^{*}}}$, with $\lim _{T^{*} \rightarrow \infty} x_{I}(2 k)=\frac{1}{1+\delta}$ and

$$
x_{I}(2 k+1)=\frac{\delta}{1+\delta} \frac{1-\delta^{T^{*}-1}}{1-\delta^{T^{*}}}, \text { with } \lim _{T^{*} \rightarrow \infty} x_{I}(2 k+1)=\frac{\delta}{1+\delta} \text {. }
$$

if $T^{*}$ is even $\quad x_{I}(2 k)=\frac{1}{1+\delta}$, and $x_{I}(2 k+1)=\frac{\delta}{1+\delta}$.

If voters have a finite memory, after the third election three groups of voters are formed (see Figure 2), and they define the behavior of the voters for all remaining elections: leftists, rightists, and swing voters. When voters recall an even number of elections, the recency effect alone determines the results of the elections. On the other hand, when voters recall an odd number of elections, a party in office will lose next election due to both recency and frequency effects. In the latter case we find that there are less partisans and more swing voters than in the former. The reason is, again, that the effect of "ideology" is stronger when it is countered by recency effect alone than in the case where both recency and frequency effects prod the voters to switch.

$7 \quad$ Notice that the cumulative dissatisfaction indices of the voters as described in the rest of the paper are a special case of these last ones, in which voters are assumed to have an infinite memory. 


\section{MULTIPARTY COMPETITION}

An assumption of the model is to restrict the electoral competition to two parties. The analysis of multiparty electoral competition will allow us to test the robustness of the results found for two party competition, to study the relationship between the policy space and the number of different "ideologies" that may emerge; and lastly, to study the effect of a party splitting into two formally distinct parties.

We describe the analysis of the same formal model for the case of threeparty competition ${ }^{8}$. Formally, the differences between the two models are: (i) the number of parties $p \in\{a, b, c\}$, (ii) the discount factor $\delta=1$, and (iii) the distribution of the voters' relative dissatisfaction indices. As before, each voter is characterized by a relative dissatisfaction index, and we assume that there is a continuum of voters. In order to solve the model for three-party competition we need to assume that the distribution of the relative dissatisfaction indices of the voters is uniform on the interval $[0,1]$. Voter $i$ will vote for the party that maximizes:

$$
U_{i}^{T}(p)= \begin{cases}u_{i}\left(w^{t-1}\right)+U_{i}^{T-1}(p) \text { if } p \text { wasin office at } t-1 \\ U_{i}^{T-1}(p) & \text { if } p \text { wasnot in office at } t-1\end{cases}
$$

The results of this model of three-party competition are qualitatively the same as the ones presented for two parties, and can be easily generalized to more than three parties. Furthermore, if we assume that parties and candidates have different objectives, an additional result of the three-party model shows the formation of parties, as infinitely lived agents with a certain ideology, out of the competition of myopic candidates freely choosing policy positions.

Since elections take place over time, we can consider the fact that candidates and parties have different "life" horizon. While candidates typically cannot be reelected forever, parties can. Thus it is natural to make a distinction between candidates and parties with respect to their objective functions. Since candidates cannot be reelected over and over again, they behave myopically. It is assumed that the objective of the candidates while in office is to maximize the

8 The proofs of this section can be found in Aragones (1993). 
proportion of votes that their party will get in next election. Parties, on the other hand, care about the future and they try to maximize the number of times they will be in office over time. Candidates may be viewed as players in a one period game, whereas parties - as players in an infinite period one. Each party presents one candidate for each election. A single winner ${ }^{9}$ is elected under plurality rule, and has to choose a policy to implement in the set $\{0,1\}$. We will see that the different objectives of parties and candidates are compatible. Furthermore, the choices that candidates make while in office result in the formation of different ideologies for different parties.

First we present a solution of the candidates competition that relies on the assumption that candidates are loyal in the following sense: when they are indifferent between policies of type 0 and 1 they will choose the policy that the party has chosen in the past (this turn out to be well defined). In this case the solution shows that no party mixes policies of different types, i.e., if a party starts choosing a policy of type 1 it will continue choosing this type of policy for ever. Let $k_{1}^{p}(t)$ be the number of times that party $p$ was in power and chose policy 1 up to time $t$. Similarly, we define $k_{0}^{p}(t)$ and $k^{p}(t)=k_{0}^{p}(t)+k_{1}^{p}(t)$. Thus, for every $t, t=k_{0}^{a}(t)+k_{1}^{a}(t)+k_{0}^{b}(t)+k_{1}^{b}(t)+k_{0}^{c}(t)+k_{1}^{c}(t)$.

Theorem 4: Competition of loyal candidates.

If all the candidates use loyal-stagewise maximizing strategies, we have the following results up to any permutation of parties and/or of policies:

I. For all $t=4 k, k=1,2, \ldots, k_{0}^{a}(t)=k^{a}(t)=k, k_{0}^{b}(t)=k^{b}(t)=k$ and $k_{1}^{c}(t)=k^{c}(t)=2 k$

II. $\lim _{t \rightarrow \infty} \frac{k^{a}(t)}{t}=\lim _{t \rightarrow \infty} \frac{k^{b}(t)}{t}=\frac{1}{4}$ and $\lim _{t \rightarrow \infty} \frac{k^{c}(t)}{t}=\frac{1}{2}$

Now we drop the assumption of loyalty and in the long run we have a similar result, i.e., in the first periods one of the parties may switch between the two types of policies but at some point it chooses one of them and continues with the chosen one for ever.

Theorem 5: Competition of candidates.

$9 \quad$ Ties are broken by fair lotteries. 
If all candidates use stagewise maximizing strategies, then we have the following results up to any permutation of parties and/or of policies:

I. For all $t=4 k, k=1,2, \ldots$ there exist $k_{1}$ and $k_{2}$ with $k=k_{1}+k_{2}$ and $\min \left\{k_{1}, k_{2}\right\} \leq 3$

such that $k_{0}^{a}(t)=k_{1}, k_{1}^{a}(t)=k_{2}, k_{0}^{b}(t)=k^{b}(t)=k_{1}+2 k_{2}$ and $k_{1}^{c}(t)=k^{c}(t)=2 k_{1}+k_{2}$

II. $\lim _{t \rightarrow \infty} \frac{k^{a}(t)}{t}=\lim _{t \rightarrow \infty} \frac{k^{b}(t)}{t}=\frac{1}{4}$ and $\lim _{t \rightarrow \infty} \frac{k^{c}(t)}{t}=\frac{1}{2}$

Furthermore, for all $p \in\{a, b, c\}$, if $k_{0}^{p}(t)>0$ and $k_{1}^{p}(t)>0$ for some $t$,

then $\lim _{t \rightarrow \infty} \frac{k^{p}(t)}{t}=\frac{1}{4}$.

This theorem states that two of the parties will always choose the same type of policy, regardless of how the third party chooses to mix the policies. That is, two of the parties are behaving as if they were loyal, while the third one is "almost" loyal: it will choose the same policy whenever in power, except for at most three times. At any rate, the long-run frequencies are as specified in the previous theorem; however, in case one party mixes the two types of policies, it cannot be the one that wins one half of the times.

In both cases, it is in the interest of each party to have no other party choosing the same type of policy it has decided to implement. The two solutions described above yield the same results for the long run: one of the parties chooses one type of policy and wins one half of the time and the other two parties choose policies of the other type and each wins one fourth of the time. Since, as in the previous model, we assume that parties have no ideal point to begin with, this result can be interpreted as suggesting that ideologies may emerge from the actions of the candidates when maximizing the popularity of the party in the short run.

In the solutions described above we have considered candidates as the players of the game at each stage. If parties instead of candidates were to decide on policies, their objective would be to maximize the number of times that the party wins, that is, the limit frequency of the number of times that the party is in power. They take into account that they are going to participate in all elections and so they would prefer to sacrifice some of the votes in a given period in order to increase the total number of times in office. We show that if candidates are stagewise vote-maximizers and loyal, their choices constitute a Nash equilibrium 
path in the infinite-stage game. On the other hand, when we relax the loyalty assumption this result does not hold any longer.

\section{Theorem 6: Competition of parties.}

The play generated by stage-wise maximization with loyal candidates (described in Theorem 4) is a Nash equilibrium play in a repeated game among parties, assuming they maximize the $\liminf$ of the frequency of the times they are in office.

In this model, even in the case that candidates were completely responsible for the choice of policies, their choices would not conflict with their parties' long-run objectives. Furthermore, the resulting choice of policies over time characterizes the party by an ideology: in equilibrium parties are identified with a certain type of policy. Thus, the competition of myopic candidates that behave independently of the party label assigned to them gives as a result the characterization of political parties by an ideology.

To sum, the three party model suggests the following conclusions. First, the emergence of ideologies is not an artifact of the two party model. Second, the number of "ideologies" seems to depend on the policy space, rather than on the number of parties; despite the parties' incentive to differentiate themselves from each other, no party in our model chooses to appear as "moderate," and they all choose some "extreme." Finally, our results seem to explain Duverger Law: when the policy space consists of only two points, there is "no room" for a third party.

\section{CONCLUDING REMARKS}

We start by assuming that all parties are identical, that they do not have preferences over policies; rather, they are vote maximizers. In equilibrium parties and candidates behave as if they had ideal points, i.e., each party chooses always the same policy. If, instead, we assume that parties have non-identical preferences over policies and their objective is not only to win elections but also to implement their most preferred policies, one can show that the result will not change. Therefore, the fact that parties always choose the same policy is compatible with (at least) two theories: (i) the parties are only interested in vote maximization, and ideologies "emerge" from strategic considerations; and (ii) 
parties do have ideologies to begin with, and these determine their initial choices, since vote maximization leaves them indifferent between the two policies; however, in later stages vote maximization and ideological considerations coincide.

If cumulative dissatisfaction is the driving force behind voters' decisions, it stands to reason that an entrant -- or an old party in new guise -- would win the election just by having no past. This counter-intuitive feature is an artifact of the absence of platforms in our model. Indeed, the model attempted to abstract away from platforms in order to focus on parties' performance in power. However, when entry is possible, one cannot ignore the fact that something is known even about a "new" party. Our model may be generalized to incorporate platforms, in such a way that the voters' decision rule take them into account. Specifically, one may assume that voters have some similarity assessment over parties, which is based on declared platforms. When a party is evaluated, its attractiveness is partly determined by past performance of other parties it resembles. Thus, a new party who has an identical platform to an "old" one will be perceived as if it were already in power and has performed like the latter.

The introduction of campaigns in the model could also be done in order to allow parties to retract from previous failures. The parties would be able to use the platforms to compensate for the negativity effect, and recharge voters with partisan sentiments. This would be a more realistic and complicated set up. The analysis of the negativity effect suggests that parties have an interest in developing campaigns that would soften the voters' sentiments. Thus, in real elections the consequences of the negativity effect won't appear as strong as the results of the model.

As a result of the choices made by the candidates in office, the behavior of the voters over time has a specific tendency. Voters may start out by switching among the two parties, but some voters find themselves supporting one of the parties from some point on. Thus, the dynamics of this model explain the eventual identification of voters as either "leftists", "rightists" or "swing" voters. Using Gallup party identification figures, Mueller (1973) claims that, except for the remarkable first term of Eisenhower and the very short term of Johnson, all presidents have experienced a decline in the number of congenial party identifiers during their time in office: out-party identifiers respond quickly to 
disapproval of the president while in-party identifiers respond more slowly. In our model, the behavior of the voters is also along these lines. A process is described by which more extreme voters become identified with a "right" or "left" bloc, while a proportion of voters around the median always switches between the two parties.

Other variations of retrospective voting have been suggested in analyzing how voters ought to behave if they wish to get their representatives to pursue their interests. The solution is an optimal decision rule for the voters given that they know the objective function of the parties. Ferejohn (1986) and AustenSmith and Banks (1989) are two examples. In our model, we assume that voters use very little information to make their decision. They do not know the objectives that define parties' behavior and they use a very simple rule to evaluate parties based on past performance. Even though the decision rule of the voters uses all the information in the voters' memory about past performance of the parties, at each point of time a voter only has to remember one number for each party, which represents the evaluation of the party by the voter.

We have supported our assumptions on the preferences of the voters with empirical evidence, but it is not easy to find empirical evidence of all the results. Even though the behavior of the voters predicted by the solution of the model seems reasonable, and the same patterns have been observed in some empirical studies (Mueller (1973), Campbell et al. (1960)), it is more difficult to accept the results about the behavior of the parties as realistic. The reason is that, because of the simplicity in the modelling of the parties, the solution describes a rather extreme behavior. Since the focus of our analysis is the consequences of the negativity effect, we should not find this surprising. In real elections there are many factors that play a role on the behavior of the voters and parties that we have not considered here. Many of those will compensate for the negativity effect, and in some cases they may even offset and we will have to take into account a positivity effect (Klein and Sedek (1994)). But there would be cases in which the negativity effect matters and it could help us in explaining the observed behavior. Be that as it may, we should always consider the possibility of the negativity effect when analyzing any particular electoral behavior. 


\section{REFERENCES}

ABELSON, R.P. and A. LEVI (1985) "Decision Making and Decision Theory". In G. Lindzey and E. Aronson (Eds.), The Handbook of Social Psychology (3rd ed, Vol 1). New York: Random House.

ALESINA, A. and J. SACHS (1988) "Political Parties and the Business Cycle in the United States, 1948-1984". Journal of Money, Credit, and Banking (February): $\quad$ 63-84.

ARAGONES, E. (1993) “A Dynamic Model of Political Competition". Discussion Paper No. 1044, The Center for Mathematical Studies in Economics and Management Science. Northwestern University.

AUSTEN-SMITH, D. and J. BANKS (1989) "Electoral Accountability and Incumbency". Models of Strategic Choice in Politics. Ed: P. Ordeshook.

BECK, N. (1982) "Parties, Administrations, and American Economic Outcomes". American Political Science Review 76 (March): 83-94.

BLOOM , H.S. and H.D. PRICE (1975) "Voter response to short-term economic conditions: The asymmetric effect of prosperity and recession". American Political Science Review, 59 (March): 7-28.

CAMPBell, A., P.E. CONVERSE, W.E. MilleR and D.E. STOKES (1960) The American Voter. New York: John Wiley and Sons.

CHAPPEL, H. and W. KEECH (1986) "Party Differences in Macroeconomic Policies and Outcomes". American Economic Review (May): 71-74.

DOWNS, A. (1957) An Economic Theory of Democracy. New York, Harper and Row.

FEREJOHN, J. (1986) "Incumbent Performance and Electoral Control". Public Choice, 50: 5-25.

FIORINA, M.P. (1981) Retrospective Voting in American National Elections. New Haven and London, Yale University Press. 
FREY, B.S. and F. SCHNEIDER (1978) "An Empirical Study of Politico-economic Interaction in the U.S." Review of Economics and Statistics 60: 174-83.

GILBOA, I. and D. SCHMEIDLER (1993) "Case-Based Consumer Theory". Northwestern University.

HIBBS, D. (1977) "Political Parties and Macroeconomic Policy". American Political Science Review (December): 1467-87.

JUDD, K. (1985) "The Law of Large Numbers with a Continuum of IID Random Variables". Journal of Economic Theory, 35: 19-25.

KANOUSE, D.E. and L.R. HANSON (1972) "Negativity in Evaluations". In E.E. Jones, D. Kanouse, H.H. Kelley, R.E. Nisbett, S. Valins, and B. Weiner (Eds.), Attributions: Perceiving the causes of behavior. Morristown, NJ: General Learning Press.

KERNELL, S. (1977) "Presidential Popularity and Negative Voting". American Political Science Review, 71: 44-66.

KEY, V.O. (1966) The Responsible Electorate. New York, Vintage.

KLEIN, J.G. (1991) "Negativity Effects in Impression Formation: A Test in the Political Arena". Personality and Social Psychology Bulletin, 17 (N. 4): 412-418.

KLEIN, J.G. and SEDEK, G. (1994) "When Candidate Strengths Matter: Positivity in Polish Impressions of Presidential Contenders". Northwestern University, mimeo.

LAU, R.R. (1982) "Negativity in Political Perception". Political Behavior, 4: 353-378.

LAU, R.R. (1985) "Two Explanations for Negativity Effects in Political Behavior". American Journal of Political Science, 29: 119-138.

LODGE, M., K.M. MCGRAW and P. STROH (1989) "An Impression-Driven Model of Candidate Evaluation". American Political Science Review, 83: 399-419.

MUELLER, J.E. (1973) War, Presidents, and Public Opinion. New York: Wiley.

TABELlini, G. and V. LA VIA (1989) "Money, Debt, and Deficits in the US". Review of Economics and Statistics, (February). 


\section{APPENDIX}

\section{Proof of Theorem 1}

To prove this theorem we use induction on $k$ :

At $t=0$, we have $U_{i}^{0}(a)=U_{i}^{0}(b)=0$, therefore all voters are indifferent between the two parties and vote for each one with probability $\frac{1}{2}$, which implies a tie among the two parties. Suppose that party $a$ wins the first election, party $a$ is indifferent between policies 0 and 1 , since $U_{i}^{1}(a)<U_{i}^{1}(b)=0$ for all voters and all policy choices of $a$.

Suppose that party $a$ chose policy 0 at $t=0$, then at $t=1$ we have $U_{i}^{1}(a)=-x_{i}$ and $U_{i}^{1}(b)=0$, and party $b$ wins the second election. At this time party $b$ chooses policy 1 which gives it a positive share of the votes at the next election (otherwise $U_{i}^{2}(b)<U_{i}^{2}(a)$ for almost all voters).

At $t=2$, we have $U_{i}^{2}(a)=-\delta x_{i}, U_{i}^{2}(b)=-\left(1-x_{i}\right)$. Since the relative dissatisfaction index of the indifferent voter, $x_{I}(2)=\frac{1}{1+\delta}$, is to the right of the median's, the median voter votes for party $a$, and it wins the third election. Party $a$ chooses policy 0 , which gives it a positive share of the votes at the next election (otherwise $U_{i}^{3}(a)<U_{i}^{3}(b)$ for all voters).

There are other possible results for this period given by all permutations of parties and policies at $t=0$. The result in all these cases will be the same up to permutations of the names of parties and policies.

Now, suppose that the result is true for all $t<2 k$. Then, at $t=2 k$ we have

$$
U_{i}^{2 k}(a)=-\left(\delta^{2 k-1}+\delta^{2 k-3}+\ldots+\delta\right) x_{i} \text { and } U_{i}^{2 k}(b)=-\left(\delta^{2 k-2}+\delta^{2 k-4}+\ldots+1\right)\left(1-x_{i}\right) .
$$

This implies that $x_{I}(2 k)=\frac{1+\delta^{2}+\ldots+\delta^{2 k-4}+\delta^{2 k-2}}{1+\delta+\ldots+\delta^{2 k-2}+\delta^{2 k-1}}=\frac{1}{1+\delta}$, therefore party $a$ wins the election at time $t=2 k$ and 


$$
x_{I}(2 k+1)_{w^{2 k}=0}=\frac{\delta+\ldots+\delta^{2 k-3}+\delta^{2 k-1}}{1+\delta+\ldots+\delta^{2 k-1}+\delta^{2 k}}>\frac{-1+\delta+\ldots+\delta^{2 k-3}+\delta^{2 k-1}}{-1+\delta+\ldots+\delta^{2 k-1}+\delta^{2 k}}=x_{I}(2 k+1)_{w^{2 k}=1} .
$$

(Where $x_{I}(t)_{w^{t-1}}$ denote the relative dissatisfaction index of the indifferent voter at election $t$, if the last incumbent chose policy $w^{t-1}$.) Thus, party $a$ will choose policy 0 . (Notice that the proportion of votes that party $b$ gets decreases as the relative dissatisfaction index of the indifferent voter increases.)

At $t=2 k+1$ we have

$$
U_{i}^{2 k+1}(a)=-\left(\delta^{2 k}+\delta^{2 k-2}+\ldots+1\right) x_{i} \text { and } U_{i}^{2 k+1}(b)=-\left(\delta^{2 k-1}+\delta^{2 k-3}+\ldots+\delta\right)\left(1-x_{i}\right) .
$$

Therefore $x_{I}(2 k+1)=\frac{\delta+\delta^{3}+\ldots+\delta^{2 k-3}+\delta^{2 k-1}}{1+\delta+\ldots+\delta^{2 k-1}+\delta^{2 k}}<\frac{\delta}{1+\delta}$ which implies that party $b$ wins this election and

$$
x_{I}(2 k+2)_{w^{2 k+1}=0}=\frac{\delta^{2}+\delta^{4}+\ldots+\delta^{2 k-2}+\delta^{2 k}}{-1+\delta+\ldots+\delta^{2 k}+\delta^{2 k+1}}>\frac{1+\delta^{2} \ldots+\delta^{2 k-2}+\delta^{2 k}}{1+\delta+\ldots+\delta^{2 k}+\delta^{2 k+1}}=x_{I}(2 k+2)_{w^{2 k+1}=1} \text {. }
$$

Thus, party $b$ will choose policy 1 .

At $t=2 k+2=2(k+1)$ we have:

$$
\begin{aligned}
& U_{i}^{2(k+1)}(a)=-\left(\delta^{2(k+1)-1}+\delta^{2(k+1)-3}+\ldots+\delta\right) x_{i} \text { and } \\
& U_{i}^{2(k+1)}(b)=-\left(\delta^{2(k+1)-2}+\delta^{2(k+1)-4}+\ldots+1\right)\left(1-x_{i}\right) .
\end{aligned}
$$

(i) and (ii) are direct implications of this result.

\section{Proof of Theorem 2:}

From the proof of Theorem 1 we know that at election $t=2 k$ we have that $x_{I}(2 k)=\frac{1}{1+\delta}$. Similarly, from Theorem 1 we know that at election $t=2 k+1$ we have that $x_{I}(2 k+1)=\frac{\delta+\delta^{3}+\ldots+\delta^{2 k-3}+\delta^{2 k-1}}{1+\delta+\ldots+\delta^{2 k-1}+\delta^{2 k}}=\frac{\delta}{1+\delta} \frac{1-\delta^{2 k}}{1-\delta^{2 k+1}}$. The properties of this last expression can be easily checked.

\section{Proof of Theorem 3}

When voters recall a finite number of elections $T^{*}$, Theorem 1 still describes the solution for all elections up to $T^{*}$. At election $T^{*}+1$ voters recall elections 
$\left\{1, \ldots, T^{*}\right\}$. If $T^{*}$ is odd, party $b$ won the last election, and the voters' evaluations of the parties are

$$
U_{i}^{T^{*}+1}(a)=-\left(\delta^{T^{*}-2}+\delta^{T^{*}-4}+\ldots+\delta\right) x_{i} \text { and } U_{i}^{T^{*}+1}(b)=-\left(\delta^{T^{*}-1}+\delta^{T^{*}-3}+\ldots+1\right)\left(1-x_{i}\right) .
$$

Which implies that $x_{I}\left(T^{*}+1\right)=\frac{1}{1+\delta} \frac{1-\delta^{T^{*}+1}}{1-\delta^{T^{*}}}>\frac{1}{1+\delta}$, party $a$ wins the election and chooses policy 0 . At election $T^{*}+2$ voters recall elections $\left\{2, \ldots, T^{*}+1\right\}$, and their evaluations of the parties are

$$
U_{i}^{T^{*}+2}(a)=-\left(\delta^{T^{*}-1}+\delta^{T^{*}-3}+\ldots+1\right) x_{i} \text { and } U_{i}^{T^{*}+2}(b)=-\left(\delta^{T^{*}-2}+\delta^{T^{*}-4}+\ldots+\delta\right)\left(1-x_{i}\right) .
$$

Which implies that the relative dissatisfaction index of the indifferent voter is $x_{I}\left(T^{*}+2\right)=\frac{\delta}{1+\delta} \frac{1-\delta^{T^{*}-1}}{1-\delta^{T^{*}}}<\frac{\delta}{1+\delta}$, and party $b$ wins the election.

Since the choice of the voters are stationary, when their memory is finite, we will have that for all $k=1,2, \ldots \quad x_{I}(2 k)=\frac{1}{1+\delta} \frac{1-\delta^{T^{*}+1}}{1-\delta^{T^{*}}}$ and $x_{I}(2 k+1)=\frac{\delta}{1+\delta} \frac{1-\delta^{T^{*}-1}}{1-\delta^{T^{*}}}$.

Similarly we can solve the case of an even number of elections in the memory of the voters. 